\title{
A Multistep Model of Resilience Development
}

\author{
Mohd. Muzamil Kumar ${ }^{1 *}$, Dr. Shawkat Ahmad Shah ${ }^{2}$
}

\section{ABSTRACT}

Every year, natural disasters create havoc and threaten the strength \& stability of communities throughout the world .The 2014 floods that struck Kashmir also created a lot of material and psychological devastation, by taking away many precious lives \& destroying homes in its wake. Considering the same, the survivors of the floods were left not only with the challenges like unfinished repairs, lingering insurance claim disputes \& financial strain but also the severe psychological problems like depression and trauma. Amidst such circumstances the depth of the psychological capital in the community has an important role to play. Broadly speaking, building resilience can be an effective response in this regard. As per Aldrich (2012) what contributes to efficient reconstruction is more important than ever. In this context the present study proposes a multi-step model of resilience development among flood affected people. As the model is grounded in principles of positive psychology and takes into consideration the Indian cultural context, it is hoped that, the same can be made use of by the mental health professionals in order to help the victims to effectively deal with the challenges by focusing on resilience development.

Keywords: Resilience, Floods, Mental Health.

The 21st century has already witnessed multiple earthquakes, floods, tsunamis and other natural disasters on large scale and millions of people have been affected worldwide. Considering the uneven climatic changes, urban migration, population growth and increased scarcity of natural resources, it is expected that the intensity and frequency of disasters is likely to increase. The region of Jammu and Kashmir is no exception to this as reflected by the material \& psychological devastation caused by 2014 floods. Many precious lives were lost and a huge chunk of population was left homeless. The survivors of the floods were left not only with the challenges like unfinished repairs, lingering insurance claim disputes \& financial strain but also the severe psychological problems like depression and trauma. Amidst such circumstances the depth of the psychological capital in the community has an important role to play. Broadly speaking, building resilience can be an effective response in this regard. As per Aldrich(2012) what contributes to efficient reconstruction is more important than ever, besides this building resilience in the community is a much needed \& potentially effective response in curbing the menace caused by disasters. It aims at not only making the people able to withstand disaster and rebuild infrastructure but also to rebuild the ties that are the foundations of any community. As

\footnotetext{
${ }^{1}$ Ph. D Research Scholar, Department of Psychology, University of Kashmir, Hazratbal, Srinagar, J\&K

${ }^{2}$ Associate Professor, Department of Psychology, University of Kashmir, Hazratbal, Srinagar, J\&K *Corresponding Author

(C) 2015 I M Kumar, S Shah; licensee IJIP. This is an Open Access Research distributed under the terms of the Creative Commons Attribution License (http://creativecommons.org/licenses/by/2.0), which permits unrestricted use, distribution, and reproduction in any Medium, provided the original work is properly cited.
} 
far as the conceptual underpinnings of resilience are concerned, it is defined as a way of coping with danger or distress. A resilient individual possess a staunch acceptance of reality a deep belief, often buttressed by strongly held values, that life is meaningful and an uncanny ability to improvise (Coutu,2002;Shahnawaz \& Jafri,2009).Luthans(2002) stated that resilience is "the capacity to rebound or bounce back from adversity, conflict, failure, or even positive events,progress, and increased responsibility. The main characteristics of resilient people include ability to bounce back and recover from problems like illnesses, natural disasters, divorce ,job loss etc. Besides this they have a tendency to see problems as opportunities, to follow "where there is a will, there is a way" attitude, to hang tough when things are difficult, to see small windows of opportunity and making the most of them etc. Research supports that resilience enhances various aspects of human functioning, especially those related to posttraumatic coping and adaptation. Tedeschi (1998) and Luthans et al (2007) have emphasized that resilient people use adversities as a 'springboard' to reach higher ground. As per Barbara Fredrickson positive emotions are the "fuel" for resilience and they help people to find meaning in their life events. The various strategies for developing resilience among the individuals as per Masten and Reed (2002) include asset- focused strategies, risk-focused strategies and process-focused strategies. Asset-focused strategies focus on the enhancement of perceived and actual level of assets and resources that increase the probability of positive outcomes. From positive psychological perspective, these assets may include positive psychological capital components of hope, efficacy, resilience and optimism. Risk-focused strategies of resilience aim at the proactive reduction of exposure to risk through various protective mechanisms. Lastly, process-focused strategies primarily aim to identify, select, develop, employ and maintain the proper mix of assets in managing risk factors. In this context, the present study proposes a multi-step model of resilience development among flood affected people. As the model is grounded in principles of positive psychology and takes into consideration the Indian cultural context, it is hoped that, the same can be made use of by the mental health professionals in order to help the victims to effectively deal with the challenges by focusing on resilience development.

\section{METHODOLOGY}

The study relied on the conceptualization of secondary data sources pertaining to development of resilience, so as to formulate a new model which is grounded in principles of positive psychology and takes into consideration the Indian cultural context. The proposed model emphasizes various focal points where affirmative action can be taken so as to promote resilience at the grass root level.

\section{MODEL DESCRIPTION}

The model proposed in the present study is designed to help the flood affected people to build the positive psychological construct of resilience in them. The framework of the model rests on the assumption that a client suffering from any problem or setback has both positive and negative attributes and it is the duty of counselors and therapists to unveil them, so as to help clients to 
focus on construction of resilient beliefs and dismantling of beliefs and behaviours that serve as roadblocks to resilience. The description of the various steps of the model is presented as follows.

\section{Addressing Negativity}

As per the concept of negativity bias, negative stimuli like the traumatic events have a greater effect on one's psychological state and processes than the positive stimuli irrespective of intensity(Baumeister, Finkenauer \& Vohs,2001; Leuicka,Czapinski \& Peters,1992 ; Rozin \& Royzman, 2001). Thus, as something positive will generally have less impact on a person's behaviour than something equally emotional but negative, this tilt of balance towards the negativity needs to be addressed. e.g. one of the typical observations after the post flood period in $\mathrm{J} \& \mathrm{~K}$ was that people used to transfer their precious items to the safer places, if it rained for more than two days or so, in a way the rainfall was increasingly perceived as more negative, the more it continued, thereby serving as a block to resilience development. To eliminate the same, the client needs to be made aware that, although it is always good to safeguard the property but it needs to be done in a rational way rather than a stress-coping way. By doing this, the outcome will be the same but the thinking strategies will be different and resilience friendly. One important strategy in this regard is the use of Herbert Simon's decision making model, in which he talks of intelligence, choice and design while solving any problem.

\section{Magnification of Strengths}

As per Davis(1999), the various areas of competence that might serve as foundations for resilience include good health, secure attachment and basic trust in other people, interpersonal competence, cognitive competence, ability to contribute, and holding faith that your life matters and life has meaning. As per Padesky \& Mooney(2012), these areas provide a broad net with which to capture 'strengths' and the present model focuses on magnification of these strengths in the clients by making use of comparison \& reinforcement skill at regular intervals. e.g. the doctors who served the community despite the fact that their own houses had remained submerged in water can serve as an exemplar for the client who did nothing except focusing on the submerged property. Likewise a client who saved his life despite limited chances, doesn't recognize the resilience he/she had demonstrated while doing so and the same needs to be brought to his/her awareness so as to ensure further resilience development. Thus the second step of the model advocates sustenance of the past resilience demonstrated by the client and the same can come to the forefront by either administration of short \& standardized instruments or dialogue pertaining to daily activities of the client. Once the strength is magnified, it is imperative on the therapist to give positive feedback; so as to prompt the client fell free to reveal more strength.

\section{Transformation of resilience}

This step of the model rests on the assumption that the resilience demonstrated by a person in dealing with one challenging circumstance can be transferred in dealing with the future 
challenging circumstances. It is strongly emphasized that if one is too resilient that he could save himself from any disastrous event, why he cannot be resilient in overcoming the trauma left by the same. This step is grounded in the framework of O'Leary, V., Ickovics, J.(1995) as per which returning to baseline quality of life is very essential. This is also in line with the research carried out by Southwick \& Charney(2012), who in a study of prisoners of war from Vietnam, showed that participants developed much less pathological symptoms than expected. Appropriate trainings grounded in religious beliefs of the client can also prove effective in helping the clients to transform resilience.

\section{Adaptation}

Lastly, it is imperative on the therapists to recommend resilience as a tool to adapt to the setbacks caused by any disaster as it is the only option to move ahead in life. It has to be made clear that ruminating over the trauma can yield nothing more than further trauma and it is therefore very essential to use various setbacks as stimuli to practice resilience rather than succumbing to them. It is emphasized that once the client starts practicing resilience, it begets more resilience and the cycle of "negative stimulus- positive response" becomes self operational with the passage of time. Thus practicing resilience becomes the hallmark of the client while dealing with the adversities like flood aftermath scenarios.

\section{CONCLUSION}

Though, the model proposed in the present study, can stand alone as an approach to help people, it never means that this should replace the classical cognitive behavioural therapy approaches or the strengths based approach of Padesky \& Mooney(2012). The major focus of the model was to adopt a design that suits the Indian cultural context, wherein the western techniques are shunned as too challenging. It can prove more effective in case of clients who reflect lack of ability to capitalize on already demonstrated resilience. It is hoped that, the same can be made use of by the mental health professionals in order to help the flood victims to effectively deal with the challenges by focusing on resilience development. Besides this, it is expected that concerned researchers \& stake holders can investigate the utility of this model and provide suggestions for refining the same, so that the clients can be benefitted in a more appropriate manner.

\section{REFERENCES}

Aldrich,D.P.(2012).Building Resilience- social capital in post disaster recovery. Springer Tokyo Heidelberg New York Dordrecht London.

Baumeister, R. F. Finkenauer, C., Vohs, K.D. (2001). Bad is stronger than good. Review of General Psychology 5 (4), 323-370.

Coutu, D. (2002). How resilience works. Harvard Business Review, 80(5), 45-55.

Davis, N.J. (1999). Resilience: Status of research and research-based programs. Working paper, Center for Mental Health Services, Substance Abuse and Mental Health Services Administration, U.S. Department of Health and Human Services; Rockville, MD. 
Lewicka, M., Czapinski, J., Peeters, G. (1992). Positive-negative asymmetry or When the heart needs a reason. European Journal of Social Psychology 22 (5), 425-434.

Luthans, F.(2002).Positive Organizational Behaviour, Developing and Managing Psychological Strength.Management Executive, 16, 57 - 75.

Luthans, F.(2007) .Psychological capital: Developing the Human capital edge. NewYork:Oxford university press, Inc.

Masten, A. S., \& Reed, M. J. (2002).Resilience in development. In C. R. Snyder \& S.

O'Leary, V., Ickovics, J.(1995).Resilience and thriving in response to challenge: An opportunity for a paradigm shift in women's health. Women's Health: 121-142.

Padesky, C. A. and Mooney, K. A. (2012), Strengths-Based Cognitive-Behavioural Therapy: A Four-Step Model to Build Resilience. Clin. Psychol. Psychother., 19: 283-290.

Rozin, P., Royzman, E.B.(2001). Negativity bias, negativity dominance, and contagion. Personality and Social Psychology Review 5 (4), 296-320.

Shahnawaz,M.G. \& Jafri,M.H.(2009).Psychological Capital as predictor of organizational commitment an organizational citizenship behavior.Journal of the Indian Academy of Organizational Psychology,35,78-84.

Southwick, S., Charney, D. (2012).The Science of Resilience: Implications for the Prevention and Treatment of Depression. Science, 79-82. 